\title{
Article \\ Clinical Significance of Pleural Effusion in Mycoplasma pneumoniae Pneumonia in Children
}

\author{
Seo-Hee Kim ${ }^{1} \mathbb{D}$, Eun Lee ${ }^{1,2, *}$, Eun-Song Song ${ }^{1,2}$ and Yun-Young Lee ${ }^{3}$ \\ 1 Department of Pediatrics, Chonnam National University Hospital, Gwangju 61469, Korea; \\ shkim2968@gmail.com (S.-H.K.); essong@jnu.ac.kr (E.-S.S.) \\ 2 Department of Pediatrics, Chonnam National University Medical School, Gwangju 61469, Korea \\ 3 Department of Radiology, Chonnam National University Hospital, Gwangju 61469, Korea; \\ yunyoung0219@gmail.com \\ * Correspondence: unelee@daum.net
}

check for updates

Citation: Kim, S.-H.; Lee, E.; Song, E.-S.; Lee, Y.-Y. Clinical Significance of Pleural Effusion in Mycoplasma pneumoniae Pneumonia in Children. Pathogens 2021, 10, 1075. https:// doi.org/10.3390/pathogens10091075

Academic Editors: Lawrence S. Young and Carmelo Biondo

Received: 1 July 2021

Accepted: 23 August 2021

Published: 25 August 2021

Publisher's Note: MDPI stays neutral with regard to jurisdictional claims in published maps and institutional affiliations.

Copyright: (c) 2021 by the authors. Licensee MDPI, Basel, Switzerland. This article is an open access article distributed under the terms and conditions of the Creative Commons Attribution (CC BY) license (https:// creativecommons.org/licenses/by/ $4.0 /)$.

\begin{abstract}
The clinical significance of pleural effusion in Mycoplasma pneumoniae (MP) pneumonia in children has not yet been elucidated. Herein, we investigated the clinical implications of pleural effusion in children with MP pneumonia. Overall, 150 children with MP pneumonia transferred to a tertiary hospital were enrolled in this study. Information on their clinical, laboratory, and radiological features was retrospectively obtained from medical chart reviews. In total, 24 (16.0\%) children had pleural effusion at the time of admission. The duration of fever and length of hospitalization were significantly longer in the pleural effusion group than in the non-pleural effusion group. A significantly higher proportion of individuals in the pleural effusion group had a poor response to stepwise treatment for MP pneumonia. The mean C-reactive protein, lactate dehydrogenase, and aspartate aminotransferase levels were significantly higher in the pleural effusion group than in the non-pleural effusion group at admission. The prevalence of severe pneumonia, defined on the basis of the extent of pneumonic lesions on chest radiography, was higher in the pleural effusion group than in the non-pleural effusion group. However, there was no significant intergroup difference in the proportion of macrolide-resistant MP cases or respiratory viral coinfections. The presence of pleural effusion in children with MP pneumonia indicated a more severe clinical course and poor treatment response. The results of the present study would help in the creation of a therapeutic plan and prediction of the clinical course of MP pneumonia in children.
\end{abstract}

Keywords: children; Mycoplasma pneumoniae; pleural effusion; pneumonia

\section{Introduction}

Mycoplasma pneumoniae (MP) is one of the most common causes of communityacquired pneumonia in children [1]. MP infections present as cyclic epidemics every 3-7 years, depending on the geographic location [2]. MP infection is considered a benign or self-limiting disease; however, the prevalence of refractory MP pneumonia, characterized by persistent fever and/or disease progression despite appropriate treatment with antibiotics and immunomodulators, has been increasing [3-5]. The prevalence of macrolideresistant MP (MRMP) pneumonia has also been increasing [6]. Owing to the absence of a cell wall in MP, antibiotics effective against MP infections are limited. The combination of these factors makes it challenging to treat MP pneumonia and reduce its complications.

To improve the clinical outcomes of MP pneumonia, previous studies aimed to determine the predictive factors for clinical course, treatment response, and prognosis [7]. In addition, radiological findings combined with clinical characteristics and laboratory findings can be useful in predicting the clinical course and treatment response in children with MP pneumonia. However, studies on the clinical implications of chest radiographic findings are limited [8]. Pleural effusion, one of the complications of community-acquired pneumonia, can occur during the clinical course of MP pneumonia [9-13]. A previous 
study reported that MP was the causative pathogen in 19\% of the cases of complicated parapneumonic effusion and empyema [12]. Another study reported that MP pneumonia requiring intensive care unit admission in children was associated with a higher prevalence of pleural effusion than that not requiring intensive care unit admission $(65 \%$ vs. $10 \%$, $p<0.001$ ) [10]. However, studies comparing the clinical features and radiological and laboratory findings according to the pleural effusion status in MP pneumonia are lacking; the availability of such information would be helpful in identifying the clinical significance of pleural effusion in children with MP pneumonia. Therefore, the present study investigated the clinical implications of pleural effusion in children with MP pneumonia by comparing the clinical, laboratory, and radiological features of MP pneumonia in relation to the pleural effusion status.

\section{Materials and Methods}

\subsection{Study Population}

This study enrolled 150 children with MP pneumonia who were admitted to Chonnam National University Hospital between May 2019 and March 2020. All the children were previously healthy, without any chronic respiratory diseases, except eight children with physician-diagnosed asthma. Among the total population diagnosed with MP pneumonia, $16.0 \%(n=24)$ had pleural effusion on chest radiographs at the time of admission; the patients with pleural effusion were referred from other hospitals. The clinical manifestations and the laboratory and radiological findings were retrospectively obtained through medical chart reviews.

MP pneumonia was defined using the following three criteria: (1) acute respiratory symptoms, including fever, cough, and/or sputum; (2) proven MP infection based on the results of MP-specific IgM using blood samples and polymerase chain reaction (PCR) analysis of the sputum samples; and (3) abnormal chest radiograph and/or abnormal findings on physical examination, including abnormal breathing sounds. The presence of pleural effusion was diagnosed based on chest radiography findings [14,15]. The local Institutional Review Board (IRB) approved this study and waived the need for informed consent because of the retrospective study design (IRB No. CNUH-2019-261).

\subsection{Definition}

Severity of pneumonia was defined based on the extent of pneumonic lesions on chest radiography as follows: mild, pneumonic lesions in less than one-fourth of the total lung field; moderate, pneumonic lesions in more than one-fourth but less than one-third of the total lung field; and severe, pneumonic lesions in more than one-third of the total lung field. All the patients were treated using stepwise treatment for MP pneumonia as follows: (1) initial treatment with macrolides, preferably azithromycin $(10 \mathrm{mg} / \mathrm{kg} /$ day, once orally for 3 days), regardless of the macrolide resistance of MP, and $1-2 \mathrm{mg} / \mathrm{kg} /$ day (maximum $30 \mathrm{mg} /$ dose) intravenous methylprednisolone with consideration of the treatment provided by the previous clinic; (2) when fever was persistent or the clinical signs and symptoms showed deterioration despite treatment with macrolides and low-dose systemic corticosteroids, ciprofloxacin or tetracyclines were introduced in cases of MRMP pneumonia; and (3) if patients responded poorly to the second-line treatment for MRMP cases or first-line treatment for macrolide-sensitive MP pneumonia cases, $10-15 \mathrm{mg} / \mathrm{kg} /$ day methylprednisolone pulse therapy was administered for three consecutive days with close observation for adverse effects associated with high-dose steroid therapy [16,17]. Treatment response was determined as "good" when the patients showed improvement on physical examination or chest radiography within 2-3 days after admission to our hospital. A "slow response" was defined as a slight improvement of respiratory symptoms and/or chest radiography findings within 1 week but not within 2-3 days of stepwise treatment of MP pneumonia. "No response or progression" was defined as no improvement or progression of respiratory symptoms and/or chest radiography findings even after 1 week of stepwise treatment for MP pneumonia [15]. Patients in the good and slow response groups were 
classified as the "response group" and those with no response to treatment or progression of MP pneumonia were classified as the "poor response group".

\subsection{Microbiological Studies}

All the patients had a confirmed MP infection based on the results obtained with a Mycoplasma pneumoniae real-time PCR kit (Biocore, Seoul, South Korea), which analyzed the enrolled patients' sputum samples [18], and of the serologic tests for MP-specific IgM using the LIAISON MP IgM kit (DiaSorin, Dublin, Ireland) [15]. Macrolide resistance was evaluated by the identification of point mutations at sites 2063 or 2064 in domain V of $23 \mathrm{~S}$ rRNA using the Mycoplasma pneumoniae real-time PCR kit (Biocore, Seoul, South Korea).

The sputum samples were analyzed for Streptococcus pneumoniae, Haemophilus influenzae, MP, Chlamydia pneumoniae, Bordetella pertussis, and Legionella pneumophila using the Seeplex PneumoBacter detection kit (Seegene Inc., Seoul, South Korea) to access the presence of respiratory bacterial coinfections [19].

\subsection{Statistical Analysis}

Binary logistic regression analysis was performed to identify the factors associated with the development of pleural effusion in MP pneumonia, selected based on the significant difference and/or factors considered clinically important. Adjustments were made for age and sex. All the statistical analyses were performed using SPSS version 25.0 for Windows (SPSS, Inc., Chicago, IL, USA). $p$-values $<0.05$ were considered significant.

\section{Results}

\subsection{Demographic Characteristics of the Study Population}

No significant differences were observed in the demographic characteristics between those with and those without pleural effusion except age at the time of diagnosis of MP pneumonia (Table 1). The mean age of the patients without pleural effusion (mean, 5.7 years; standard deviation (SD), 3.8 years) was lower than that of those with pleural effusion (mean, 7.3 years; SD, 3.4 years). Age can affect the manifestations of MP pneumonia in children. Therefore, we summarized the baseline characteristics of the study population after classifying the study population with regard to the age of 6 .

Table 1. Baseline characteristics of the study population.

\begin{tabular}{|c|c|c|c|c|}
\hline & Variables, $n(\%)$ & Pleural Effusion $(-)$ & Pleural Effusion (+) & $p$-Value \\
\hline \multirow{8}{*}{ children $<6$ years of age } & $\mathrm{N}$ & $71(91.0)$ & $7(9.0)$ & NA \\
\hline & $\begin{array}{c}\text { Age at diagnosis of MP pneumonia, } \\
\text { mean } \pm S D \text { years }\end{array}$ & $3.1 \pm 1.4$ & $3.7 \pm 1.1$ & 0.259 \\
\hline & Male, $n(\%)$ & $35 / 71(49.3)$ & $3 / 7(42.9)$ & 0.529 \\
\hline & Referred cases, $n(\%)$ & $66 / 71(93.0)$ & $7 / 7(100.0)$ & 0.617 \\
\hline & Presence of allergic diseases, $n(\%)$ & $33 / 71(46.5)$ & $3 / 7(42.9)$ & 0.587 \\
\hline & Atopic dermatitis, $n(\%)$ & $1 / 71(1.4)$ & $0 / 7(0.0)$ & 0.910 \\
\hline & Allergic rhinitis, $n(\%)$ & $32 / 71(45.1)$ & $3 / 7(42.9)$ & 0.615 \\
\hline & Asthma, $n(\%)$ & $6 / 71(8.5)$ & $0 / 7(0.0)$ & 0.558 \\
\hline \multirow{8}{*}{ children $\geq 6$ years of age } & $\mathrm{N}$ & $55(76.4)$ & $17(23.6)$ & NA \\
\hline & $\begin{array}{c}\text { Age at diagnosis of MP pneumonia, } \\
\text { mean } \pm \text { SD, years }\end{array}$ & $9.2 \pm 3.1$ & $8.7 \pm 3.0$ & 0.502 \\
\hline & Male, $n(\%)$ & $25 / 55(45.5)$ & $9 / 17(52.9)$ & 0.396 \\
\hline & Referred cases, $n(\%)$ & $55(100.0)$ & $17(100.0)$ & NA \\
\hline & Presence of allergic diseases, $n(\%)$ & $36 / 55(65.5)$ & $13 / 17(76.5)$ & 0.295 \\
\hline & Atopic dermatitis, $n(\%)$ & $2 / 55(3.6)$ & $0 / 17(0.0)$ & 0.581 \\
\hline & Allergic rhinitis, $n(\%)$ & $34 / 55(61.8)$ & $12 / 17(70.6)$ & 0.361 \\
\hline & Asthma, $n(\%)$ & $10 / 55(18.2)$ & $2 / 17(11.8)$ & 0.420 \\
\hline
\end{tabular}




\subsection{Comparison of Clinical Manifestations According to the Pleural Effusion Status}

The duration between the onset of MP pneumonia symptoms and admission as well as the total fever duration were significantly longer in the children with pleural effusion than in those without pleural effusion (Table 2). The need for supplemental oxygen was more common in the pleural effusion group $(n=4 / 24,16.7 \%)$ than in the non-pleural effusion group $(n=5 / 126,4.0 \%)(p=0.016)$. The proportion of the poor response group was significantly higher in the pleural effusion group than in the non-pleural effusion group $(p=0.005)$. There was no significant intergroup difference in the duration between symptom onset and initiation of antibiotic therapy.

Table 2. Comparison of clinical characteristics according to the presence or absence of pleural effusion in children with MP pneumonia.

\begin{tabular}{|c|c|c|c|}
\hline Variables, $n(\%)$ or Mean \pm SD & Pleural Effusion (-) & Pleural Effusion (+) & $p$-Value \\
\hline Duration between the symptom onset and admission, days & $6.1 \pm 4.0$ & $10.4 \pm 4.8$ & 0.026 \\
\hline Duration of fever during the illness, days & $6.4 \pm 3.7$ & $8.6 \pm 4.0$ & $<0.001$ \\
\hline Hemoptysis & $3 / 126(2.4)$ & $0 / 24(0.0)$ & 0.445 \\
\hline Fever & $125 / 126(99.2)$ & $24 / 24(100.0)$ & 0.661 \\
\hline Oxygen supplementation & $5 / 126(4.0)$ & $4 / 24(16.7)$ & 0.016 \\
\hline ICU admission & $0 / 126(0.0)$ & $0 / 24(0.0)$ & NA \\
\hline Need for mechanical ventilation & $0 / 126(0.0)$ & $0 / 24(0.0)$ & NA \\
\hline Response to the treatment & & & 0.005 \\
\hline Response & $114 / 125(91.2)$ & $17 / 24(70.8)$ & \\
\hline Poor response & $11 / 125(8.8)$ & $7 / 24(29.2)$ & \\
\hline Total duration of hospitalization, days & $8.2 \pm 4.0$ & $15.4 \pm 7.1$ & $<0.001$ \\
\hline $\begin{array}{l}\text { Duration between the symptom onset and start of antibiotic } \\
\text { therapy, days }\end{array}$ & $3.6 \pm 3.4$ & $3.4 \pm 3.5$ & 0.816 \\
\hline $\begin{array}{l}\text { Duration between the symptom onset and start of systemic } \\
\text { corticosteroid therapy, days }\end{array}$ & $7.4 \pm 5.3$ & $6.5 \pm 4.1$ & 0.377 \\
\hline $\begin{array}{l}\text { Duration between the start of antibiotic therapy and } \\
\text { defervescence, days }\end{array}$ & $4.0 \pm 4.0$ & $2.7 \pm 3.2$ & 0.152 \\
\hline $\begin{array}{l}\text { Duration between start of systemic corticosteroid therapy and } \\
\text { defervescence, days }\end{array}$ & $1.2 \pm 2.7$ & $0.4 \pm 0.7$ & 0.028 \\
\hline $\begin{array}{l}\text { Duration between the symptom onset and admission to our } \\
\text { hospital, days }\end{array}$ & $6.5 \pm 3.8$ & $7.6 \pm 3.6$ & 0.123 \\
\hline
\end{tabular}

ICU, intensive care unit; NA, not applicable; SD, standard deviation.

The treatment with antibiotics or a systemic corticosteroid was started earlier in the MP pneumonia with pleural effusion group than in the MP pneumonia without pleural effusion group, though the difference was not statistically significant. Defervescence occurred earlier in the MP pneumonia with pleural effusion group after a systemic corticosteroid therapy $(p=0.028)$. Defervescence also occurred earlier in the MP pneumonia with pleural effusion group after antibiotic therapy was administered, though the difference was not statistically significant. No cases complicated by pleural effusion required additional procedures for its removal.

\subsection{Comparison of Laboratory Findings at the Time of Admission by the Pleural Effusion Status}

The levels of C-reactive protein (CRP), lactate dehydrogenase (LDH), and aspartate aminotransferase (AST) at the time of admission were significantly higher and the level of lymphocytes (\%) was significantly lower in the pleural effusion group than in the non-pleural effusion group (Table 3). 
Table 3. Comparison of laboratory findings according to the presence or absence of pleural effusion in the children with MP pneumonia.

\begin{tabular}{cccc}
\hline $\begin{array}{c}\text { Variables, Mean } \pm \text { SD } \\
\text { (Range) }\end{array}$ & $\begin{array}{c}\text { Pleural Effusion }(-) \\
(\boldsymbol{n}=\mathbf{~ 1 2 6 )}\end{array}$ & $\begin{array}{c}\text { Pleural Effusion }(+) \\
(\boldsymbol{n}=\mathbf{2 4})\end{array}$ & $\boldsymbol{p}$-Value \\
\hline WBC, $\times 10^{3} / \mu \mathrm{L}$ & $9300 \pm 4700$ & $9300 \pm 4400$ & 0.934 \\
Neutrophils (\%) & $62.2 \pm 14.0$ & $67.2 \pm 18.2$ & 0.130 \\
Lymphocytes (\%) & $26.7 \pm 11.9$ & $19.5 \pm 10.7$ & 0.007 \\
Eosinophils (\%) & $1.8 \pm 2.6$ & $2.1 \pm 2.0$ & 0.536 \\
Monocytes (\%) & $8.6 \pm 3.8$ & $7.7 \pm 3.3$ & 0.282 \\
CRP, mg/dL & $2.3 \pm 3.2$ & $8.2 \pm 7.8$ & 0.002 \\
ESR, mm/h & $35.4 \pm 19.5$ & $40.6 \pm 21.0$ & 0.271 \\
Procalcitonin, ng/dL & $0.2 \pm 0.4$ & $0.4 \pm 0.5$ & 0.230 \\
LDH, IU/L & $751.1 \pm 280.2$ & $1107.8 \pm 507.2$ & 0.003 \\
AST, IU/L & $40.0 \pm 27.7$ & $74.3 \pm 64.5$ & 0.017 \\
ALT, IU/L & $29.9 \pm 35.7$ & $54.5 \pm 57.4$ & 0.053 \\
Albumin, g/dL & $5.3 \pm 1.5$ & $5.2 \pm 1.7$ & 0.866 \\
MP IgM at admission, index & $4.3 \pm 3.3$ & $5.3 \pm 3.3$ & 0.194
\end{tabular}

AST, aspartate aminotransferase; ALT, alanine aminotransferase; CRP, C-reactive protein; ESR, erythrocyte sedimentation rate; LDH, lactate dehydrogenase; MP, Mycoplasma pneumoniae; SD, standard deviation; WBC, white blood cells.

\subsection{Comparison of the Microbiological Characteristics by the Pleural Effusion Status}

There was no significant difference in the macrolide sensitivity of MP by the pleural effusion status (Table 4). Haemophilus influenzae and Streptococcus pneumoniae were two of the most commonly coinfected respiratory bacteria in the children with MP pneumonia. However, Chlamydia pneumoniae was not identified in any cases of MP pneumonia in this study. The prevalence of respiratory viral coinfection was not associated with the presence of pleural effusion in children with MP pneumonia.

Table 4. Comparison of microbiologic characteristics according to the presence or absence of pleural effusion in children with MP pneumonia.

\begin{tabular}{cccc}
\hline Variables, $\boldsymbol{n}(\mathbf{\%})$ or Mean \pm SD (Range) & $\begin{array}{c}\text { Pleural Effusion } \\
(-)\end{array}$ & $\begin{array}{c}\text { Pleural Effusion } \\
(+)\end{array}$ & $p$-Value \\
\hline Macrolide sensitivity & & & 0.173 \\
MSMP & $9 / 124(7.3)$ & $0 / 24(0.0)$ & \\
MRMP & $115 / 124(92.7)$ & $24 / 24(100.0)$ & \\
Coinfection with respiratory viruses & $51 / 122(41.8)$ & $12 / 23(52.2)$ & 0.357 \\
Number of coinfected respiratory viruses & $0.5 \pm 0.7$ & $0.7 \pm 0.9$ & 0.413 \\
Rhinovirus coinfection & $28 / 126(22.2)$ & $8 / 24(33.3)$ & 0.243 \\
Adenovirus coinfection & $18 / 126(14.3)$ & $1 / 24(4.2)$ & 0.172 \\
Bacterial coinfection identified & $23 / 59(39.0)$ & $5 / 14(35.7)$ & 0.264 \\
using PneumoBacter PCR & $8 / 59(13.6)$ & $4 / 14(28.6)$ & \\
Haemophilus influenzae & $7 / 59(11.9)$ & $0 / 14(0.0)$ & \\
Streptococcus pneumoniae & $8 / 59(13.6)$ & $1 / 14(7.1)$ & \\
Both Haemophilus influenzae and & &
\end{tabular}

MP, Mycoplasma pneumoniae; MRMP, macrolide-resistant Mycoplasma pneumoniae; MSMP, macrolide-sensitive Mycoplasma pneumoniae; PCR, polymerase chain reaction; SD, standard deviation.

\subsection{Comparison of Radiological Findings by the Pleural Effusion Status}

The proportion of severe pneumonia cases, defined by the extent of pneumonic lesions on the chest radiograph, was higher in the pleural effusion group than in the non-pleural effusion group (Table 5). 
Table 5. Comparison of the radiological findings according to the presence or absence of pleural effusion in children with MP pneumonia.

\begin{tabular}{cccc}
\hline Variables, $\boldsymbol{n}(\mathbf{\%})$ & Pleural Effusion (-) & Pleural Effusion $(+)$ & $p$-Value \\
\hline $\begin{array}{c}\text { Severity of pneumonia at } \\
\text { admission based on the }\end{array}$ & & & \\
chest radiograph & & & $<0.001$ \\
Mild & $16 / 126(12.7)$ & $0 / 24(0.0)$ & \\
Moderate & $90 / 126(71.4)$ & $8 / 24(33.3)$ & \\
Severe & $20 / 126(15.9)$ & $16 / 24(66.7)$ & \\
Trend $(p)$ & $<0.001$ & & \\
Characteristics on the chest & & & \\
radiograph at the time & & & \\
of admission & & & \\
Lobar consolidation & $22 / 126(17.5)$ & $7 / 24(29.2)$ & \\
Patchy consolidation & $59 / 126(46.8)$ & $1 / 24(4.2)$ & \\
Peribronchial infiltration & $34 / 126(27.0)$ & $0 / 24(0.0)$ & \\
Diffuse nodular opacity & $3 / 126(2.4)$ & $0 / 24(0.0)$ & \\
Diffuse infiltration & $8 / 126(6.3)$ & $2 / 24(8.3)$ & 0.060 \\
Development of PTE & $2 / 126(1.6)$ & $3 / 24(12.5)$ & 0.934 \\
Development of PIBO & $15 / 126(11.9)$ & & \\
\hline
\end{tabular}

PTE, pulmonary thromboembolism; PIBO, postinfectious bronchiolitis obliterans.

\subsection{Factors Associated with Pleural Effusion in Children with MP Pneumonia}

Older age, longer duration of fever during the illness, higher CRP and LDH levels, and lower lymphocyte (\%) levels were associated with the development of pleural effusion in MP pneumonia (Table 6). In addition, oxygen supplementation, severity of pneumonia, and a lack of response to stepwise treatment for MP pneumonia were significantly associated with pleural effusion in MP pneumonia.

Table 6. Factors associated with the development of pleural effusion in children with MP pneumonia.

\begin{tabular}{lcc}
\hline \multicolumn{1}{c}{ Variables } & aOR & $p$-Value \\
\hline Age, years & $1.131(1.007-1.271)$ & 0.038 \\
Duration of fever during the illness, days & $1.196(1.080-1.323)$ & 0.001 \\
Oxygen supplementation at the time of admission & $6.023(1.426-25.439)$ & 0.015 \\
Severity of pneumonia based on the chest radiograph & & \\
at admission & & \\
$\quad$ Mild and moderate & Ref. & \\
$\quad$ Severe & $10.465(3.899-28.090)$ & $<0.001$ \\
Lymphocytes (\%) & $0.945(0.900-0.991)$ & 0.021 \\
CRP, mg/dL & $1.221(1.106-1.348)$ & $<0.001$ \\
LDH, IU/L & $1.003(1.001-1.004)$ & $<0.001$ \\
Mycoplasma IgM at the time of admission, index & $1.127(0.981-1.296)$ & 0.091 \\
Response to MP pneumonia treatment & & \\
$\quad$ Response & Ref. & \\
$\quad$ Poor response & $4.789(1.577-14.549)$ & 0.006 \\
Total duration of hospitalization, days & $1.133(1.041-1.232)$ & 0.004 \\
\hline
\end{tabular}

* Adjusted by age and sex; aOR, adjusted odds ratio; CRP, C-reactive protein; LDH, lactate dehydrogenase; NA, not applicable; Ref., reference.

\section{Discussion}

In this study, we found that the presence of pleural effusion in children with MP pneumonia suggests a more severe clinical course of MP pneumonia, reflected by a higher need for oxygen support, prolonged hospitalization and fever, poor response to stepwise treatment, increased extent of pneumonic infiltration, and abnormal blood test results, including those for LDH and CRP. However, macrolide resistance and respiratory viral coinfection were not associated with pleural effusion in children with MP pneumonia. Based on the results of the present study, prediction of the clinical course of MP pneumonia 
according to the presence of pleural effusion would be helpful in therapeutic planning for better outcomes in children with MP pneumonia.

Pleural effusion is one of the most common causes of transfer to tertiary hospitals in patients with MP pneumonia. The prevalence of pleural effusion in MP pneumonia can differ according to the characteristics of the study population. Previous studies have reported that the prevalence of pleural effusion in MP pneumonia is $20.3-20.7 \%$ [20,21], although these studies included small sample sizes. In this study, pleural effusion was observed in $16 \%$ of the pediatric MP pneumonia cases referred to our tertiary hospital. Pleural effusion in all the patients investigated in this study resolved following stepwise treatment of MP pneumonia without additional procedures regardless of the extent of pleural effusion. Considering the results of this study, pleural effusion alone might not be troublesome in the clinical course of MP pneumonia. However, a case of MP pneumonia complicated by pleural effusion might suggest a severe clinical course with poor response to MP pneumonia treatment.

Although the exact pathophysiology underlying pleural effusion in MP pneumonia has not yet been well-identified, direct invasion, continuum of the MP infection, or exaggerated immune responses might be associated with its development in patients with MP pneumonia [9]. A previous study suggested that pleural effusion caused by MP infection can be classified into two patterns: one characterized by no detection of the MP genome and lower levels of cytokines, including interleukin 18 and interleukin 8 , and the other, characterized by persistent chest disease with detection of the MP genome and higher levels of interleukin 18 and interleukin 8 [22]. In this study, we could not classify the characteristics of pleural effusion because the procedures to identify the characteristics of or drain the pleural effusion were not performed. Pleural effusion that complicated the MP pneumonia cases in this study resolved gradually with the early application of immunomodulatory drugs, such as systemic corticosteroids, which were administered as part of the stepwise treatment for MP pneumonia. The earlier defervescence observed in the MP pneumonia with pleural effusion group than in the no pleural effusion group after the administration of a systemic corticosteroid suggests that exaggerated immune responses might be associated with the development of pleural effusion in MP pneumonia. Further studies are needed to elucidate the pathophysiology of pleural effusion in MP pneumonia.

Although some studies reported predictive factors for a poor response to treatment in cases of MP pneumonia such as LDH, interleukin 18, and ferritin levels [15,23,24], to date, no study has focused on the clinical significance of pleural effusion in MP pneumonia. A previous study investigated the characteristics of pleural effusion in MP pneumonia in children and proved the presence of MP in the pleural effusion using PCR [9]. In that study, the detection of MP in the pleural effusion was associated with delayed resolution of abnormal chest radiographic findings in children with MP pneumonia [9]. In our study, the presence of pleural effusion in MP pneumonia was associated with the involvement of more higher extent of pneumonic lesions on chest radiographs at the time of admission. Based on the previous and present studies, the presence of pleural effusion in MP pneumonia might suggest the severe extent and prolonged lesions on chest radiographs.

Respiratory viral coinfection could be one of the causes for the development of pleural effusion in MP pneumonia cases; however, this study found no significant difference in the proportion of patients with respiratory viral coinfection in the groups with and without pleural effusion. Moreover, there was no significant difference in respiratory bacterial coinfection between the MP pneumonia with pleural effusion group and the MP pneumonia without pleural effusion group, although PneumoBacter PCR for the identification of respiratory bacterial coinfection was performed in only $48.7 \%(n=73 / 150)$ of the cases. Furthermore, we identified that the macrolide resistance status of MP did not affect the occurrence of pleural effusion. This study identified the microbiological characteristics of sputum samples in children with MP pneumonia complicated by pleural effusion. Since there is some debate on the effects of respiratory viral and/or bacterial coinfection on the clinical course of MP pneumonia in children $[25,26]$, further large sample- 
sized studies are needed to investigate the effects of respiratory viral and/or bacterial coinfection in MP pneumonia with pleural effusion.

This study had some limitations. First, it included only patients with MP pneumonia treated at one tertiary hospital, most of whom had been transferred from primary or secondary medical centers due to complications of MP pneumonia. This suggests the selection bias in the enrolled population because more severe cases were enrolled in this study. However, pleural effusion is common in more severe cases of MP pneumonia; therefore, the results of this study are applicable to real clinical situations. More multicenter studies are necessary to confirm the results of this study, which could help improve the prognosis of MP pneumonia in children in the era of increasing macrolide resistance of MP and refractory MP pneumonia.

\section{Conclusions}

This study identified that pleural effusion in MP pneumonia is associated with a more severe clinical course, poorer treatment response, and severe pneumonia based on the extent of pulmonary lesions, although pleural effusion in all the assessed cases resolved without the need for additional procedures. However, macrolide resistance and respiratory viral coinfection did not affect the occurrence of pleural effusion in the children hospitalized with MP pneumonia. The results of this study could help clinicians predict the clinical course and treatment responses of MP pneumonia in children.

Author Contributions: Conceptualization, S.-H.K., E.L. and Y.-Y.L.; methodology, S.-H.K., E.L. and Y.-Y.L.; software, S.-H.K., E.L. and Y.-Y.L.; validation, S.-H.K., E.L., E.-S.S. and Y.-Y.L.; formal analysis, S.-H.K., E.L., E.-S.S. and Y.-Y.L.; investigation, S.-H.K., E.L., E.-S.S. and Y.-Y.L.; data curation, S.-H.K., E.L. and Y.-Y.L.; writing—original draft preparation, S.-H.K., E.L. and Y.-Y.L.; visualization, S.-H.K., E.L., E.-S.S. and Y.-Y.L.; supervision, E.L. and Y.-Y.L.; project administration, E.L. and Y.-Y.L. All authors have read and agreed to the published version of the manuscript.

Funding: This research received no external funding.

Institutional Review Board Statement: The study was conducted in accordance with the guidelines of the Declaration of Helsinki and approved by the Institutional Review Board (IRB) of Chonnam National University Hospital (IRB No. CNUH-2019-261, 12 December 2019).

Informed Consent Statement: Informed consent was waived due to the retrospective nature of medical chart reviews and approved by the Institutional Review Board (IRB) of Chonnam National University Hospital (IRB No. CNUH-2019-261).

Data Availability Statement: Please refer to the suggested Data Availability Statements in section "MDPI Research Data Policies" at https:/ / www.mdpi.com/ethics (accessed on 1 August 2021).

Acknowledgments: The authors thank all the participants for being part of this research during a very stressful situation.

Conflicts of Interest: The authors declare no conflict of interest with regard to this study.

\section{References}

1. Lee, E.; Kim, C.H.; Lee, Y.J.; Kim, H.; Kim, B.; Kim, H.Y.; Kim, Y.; Kim, S.; Park, C.; Seo, J.; et al. Annual and seasonal patterns in etiologies of pediatric community-acquired pneumonia due to respiratory viruses and Mycoplasma pneumoniae requiring hospitalization in South Korea. BMC Infect. Dis. 2020, 20, 132. [CrossRef]

2. Uldum, S.A.; Bangsborg, J.M.; Gahrn-Hansen, B.; Ljung, R.; Mølvadgaard, M.; Petersen, R.F.; Svarrer, C.W. Epidemic of Mycoplasma pneumoniae infection in Denmark, 2010 and 2011. Eurosurveillance 2012, 17, 20073. [CrossRef] [PubMed]

3. Zhang, Y.; Mei, S.; Zhou, Y.; Huang, M.; Dong, G.; Chen, Z. Cytokines as the good predictors of refractory Mycoplasma pneumoniae pneumonia in school-aged children. Sci. Rep. 2016, 6, 37037. [CrossRef]

4. Zhai, Y.-Y.; Wu, S.-Z.; Yang, Y.; Yang, L.-Y.; Xu, J.-X.; Huang, Z.-H.; He, Z.-T.; Lin, Y.-N.; Chen, D.-H. An analysis of 20 clinical cases of refractory mycoplasma pneumonia in children. Ann. Palliat. Med. 2020, 9, 2592-2599. [CrossRef] [PubMed]

5. Tamura, A.; Matsubara, K.; Tanaka, T.; Nigami, H.; Yura, K.; Fukaya, T. Methylprednisolone pulse therapy for refractory Mycoplasma pneumoniae pneumonia in children. J. Infect. 2008, 57, 223-228. [CrossRef] [PubMed]

6. Lee, E.; Cho, H.-J.; Hong, S.-J.; Lee, J.; Sung, H.; Yu, J. Prevalence and clinical manifestations of macrolide resistant Mycoplasma pneumoniae pneumonia in Korean children. Korean J. Pediatr. 2017, 60, 151-157. [CrossRef] 
7. Kim, J.H.; Kim, J.Y.; Yoo, C.H.; Seo, W.H.; Yoo, Y.; Song, D.J.; Choung, J.T. Macrolide Resistance and Its Impacts on M. Pneumoniae Pneumonia in Children: Comparison of Two Recent Epidemics in Korea. Allergy Asthma Immunol. Res. 2017, 9, 340-346. [CrossRef] [PubMed]

8. Kawai, Y.; Miyashita, N.; Kubo, M.; Akaike, H.; Kato, A.; Nishizawa, Y.; Saito, A.; Kondo, E.; Teranishi, H.; Wakabayashi, T.; et al. Nationwide Surveillance of Macrolide-Resistant Mycoplasma pneumoniae Infection in Pediatric Patients. Antimicrob. Agents Chemother. 2013, 57, 4046-4049. [CrossRef] [PubMed]

9. Narita, M.; Matsuzono, Y.; Itakura, O.; Yamada, S.; Togashi, T. Analysis of mycoplasmal pleural effusion by the polymerase chain reaction. Arch. Dis. Child. 1998, 78, 67-69. [CrossRef]

10. Lee, K.-L.; Lee, C.-M.; Yang, T.-L.; Yen, T.-Y.; Chang, L.-Y.; Chen, J.-M.; Lee, P.-I.; Huang, L.-M.; Lu, C.-Y. Severe Mycoplasma pneumoniae pneumonia requiring intensive care in children, 2010-2019. J. Formos. Med. Assoc. 2021, 120, 281-291. [CrossRef] [PubMed]

11. Lin, T.-Y.; Hwang, K.P.; Liu, C.-C.; Bin Tang, R.; Lin, C.Y.; Gilbert, G.L.; Thapa, K.; Monegal, J.S.; Pirçon, J.-Y.; Van Dyke, M.K.; et al. Etiology of Empyema Thoracis And Parapneumonic Pleural Effusion in Taiwanese Children and Adolescents Younger Than 18 Years of Age. Pediatr. Infect. Dis. J. 2013, 32, 419-421. [CrossRef] [PubMed]

12. Shen, Y.-H.; Hwang, K.-P.; Niu, C.-K. Complicated parapneumonic effusion and empyema in children. J. Microbiol. Immunol. Infect. 2006, 39, 483-488. [PubMed]

13. Shuvy, M.; Rav-Acha, M.; Izhar, U.; Ron, M.; Nir-Paz, R. Massive empyema caused by Mycoplasma pneumoniae in an adult: A case report. BMC Infect. Dis. 2006, 6, 18. [CrossRef] [PubMed]

14. Karkhanis, V.S.; Joshi, J.M. Pleural effusion: Diagnosis, treatment, and management. Open Access Emerg. Med. 2012, 4, 31-52. [CrossRef] [PubMed]

15. Lee, E.; Lee, Y. Predictive Factors of the Responses to Treatment of Mycoplasma pneumoniae Pneumonia. J. Clin. Med. 2021, 10, 1154. [CrossRef]

16. Tsai, T.-A.; Tsai, C.-K.; Kuo, K.-C.; Yu, H.-R. Rational stepwise approach for Mycoplasma pneumoniae pneumonia in children. J. Microbiol. Immunol. Infect. 2020, 54, 557-565. [CrossRef]

17. Pereyre, S.; Goret, J.; Bebear, C. Mycoplasma pneumoniae: Current Knowledge on Macrolide Resistance and Treatment. Front. Microbiol. 2016, 7, 974. [CrossRef]

18. Jeong, J.E.; Soh, J.E.; Kwak, J.H.; Jung, H.L.; Shim, J.W.; Kim, D.S.; Park, M.S.; Shim, J.Y. Increased procalcitonin level is a risk factor for prolonged fever in children with Mycoplasma pneumonia. Korean J. Pediatr. 2018, 61, 258-263. [CrossRef]

19. Park, J.; Kim, J.K.; Rheem, I.; Kim, J. Evaluation of Seeplex Pneumobacter multiplex PCR kit for the detection of respiratory bacterial pathogens in pediatric patients. Korean J. Lab. Med. 2009, 29, 307-313.

20. Fine, N.L.; Smith, L.R.; Sheedy, P.F. Frequency of Pleural Effusions in Mycoplasma and Viral Pneumonias. N. Engl. J. Med. 1970, 283, 790-793. [CrossRef]

21. Miyashita, N.; Sugiu, T.; Kawai, Y.; Yamaguchi, T.; Ouchi, K. Radiographic Features of Mycoplasma pneumoniae Pneumonia: Differential Diagnosis and Performance Timing. BMC Med. Imaging 2009, 9, 7. [CrossRef]

22. Narita, M.; Tanaka, H. Two Distinct Patterns of Pleural Effusions Caused by Mycoplasma pneumoniae Infection. Pediatr. Infect. Dis. J. 2004, 23, 1069. [CrossRef] [PubMed]

23. Choi, Y.-J.; Jeon, J.-H.; Oh, J.-W. Critical combination of initial markers for predicting refractory Mycoplasma pneumoniae pneumonia in children: A case control study. Respir. Res. 2019, 20, 1-9. [CrossRef]

24. Lu, A.; Wang, C.; Zhang, X.; Wang, L.; Qian, L. Lactate Dehydrogenase as a Biomarker for Prediction of Refractory Mycoplasma pneumoniae Pneumonia in Children. Respir. Care 2015, 60, 1469-1475. [CrossRef] [PubMed]

25. Zhang, X.; Chen, Z.; Gu, W.; Ji, W.; Wang, Y.; Hao, C.; He, Y.; Huang, L.; Wang, M.; Shao, X.; et al. Viral and bacterial coinfection in hospitalised children with refractory Mycoplasma pneumoniae pneumonia. Epidemiol. Infect. 2018, 146, 1384-1388. [CrossRef] [PubMed]

26. Zhou, Y.; Wang, J.; Chen, W.; Shen, N.; Tao, Y.; Zhao, R.; Luo, L.; Li, B.; Cao, Q. Impact of viral coinfection and macrolide-resistant mycoplasma infection in children with refractory Mycoplasma pneumoniae pneumonia. BMC Infect. Dis. 2020, 20, 633. [CrossRef] 